\title{
Comparison of lung volume in Greek swimmers, land based athletes, and sedentary controls using allometric scaling
}

\author{
Michael Doherty, Lygeri Dimitriou
}

\begin{abstract}
Objective-To compare lung volumes in a large cross sectional sample of Greek swimmers, land based athletes, and sedentary controls by means of allometric scaling.

Methods-Four hundred and fifty nine asymptomatic Greek children and young adults (age 10-21 years), including 159 swimmers, 130 land based athletes, and 170 sedentary controls, performed forced expiratory manoeuvres into a portable spirometer. Measurements included forced vital capacity, forced expiratory volume in one second $\left(F E V_{1.0}\right)$, and peak expiratory flow. Body mass and stature were also measured using standardised anthropometric techniques.
\end{abstract}

Results-Logarithmic transformations showed that $\ln \mathrm{FEV}_{1,0}$ was highly related to In stature in males and females $(r=0.93$ and 0.86 respectively, $P<0.001$ ) and were used to determine the exponent in an allometric equation which also included age and age $^{2}$. Resulting power functions, $\mathrm{FEV}_{1.0}$ /stature ${ }^{\mathrm{b}}$, were $0.64(0.18) \mathrm{litres} / \mathrm{m}^{2.69}$ and $0.33(0.24)$ litres $/ \mathrm{m}^{2.32}$ for males and females respectively (mean (SE)). The male and female swimming groups had larger $F_{1.0}$ than both land based athletes and sedentary controls (one way analysis of variance, $P<0.001)$. In addition, male national standard swimmers $(n=38)$ had superior $F E V_{1.0}$ in comparison with male non-national standard swimmers $(n=24$; $t$ test, $P<0.05$ ). However, when years of swimming training was controlled for by analysis of covariance, the difference in FEV $_{1.0}$ between the two groups was no longer evident.

Conclusions-Swimmers have superior FEV $_{1.0}$ independent of stature and age in comparison with both land based athletes and sedentary controls. In addition, male national standard swimmers have superior $F E V_{1.0}$ independent of stature and age in comparison with male non-national standard swimmers. When years of training is controlled for, the difference in $F E V_{1.0}$ between the two groups is no longer evident. This suggests that the years of swimming training and/or the earlier age at which training begins may have a significant influence on subsequent $\mathrm{FEV}_{1.0}$ and swimming performance. However, because of the cross sectional nature of this study, the results do not exclude genetic endowment as a major determinant of the superior lung volume observed in swimmers.

(Br J Sports Med 1997;31:337-341)

Keywords: swimming physiology; intensive training; respiratory muscle strength; allometric modelling

The characteristic skeletal features of swimmers appear at an early age. Swimmers tend to be tall for their body mass ${ }^{1}$ and have high bi-acromial breadths for their age group. ${ }^{2}$ In addition, it has repeatedly been shown that static lung volume and pulmonary diffusing capacity of swimmers are greater than in age- and stature-predicted values, sedentary controls, ${ }^{3-7}$ or highly trained land based athletes. ${ }^{4-11}$ The relationship between structure and function in swimming appears self evident. Body length should provide an advantage in starting, turning, and finishing and long segments have an advantage for stroking technique. ${ }^{12}$ In land based exercise the pulmonary system is usually not considered to be a limitation to performance. ${ }^{13}$ In addition, longitudinal studies of subjects involved in land based activities show lung volume to be unaffected by short term training. ${ }^{1+-17}$ However, in swimmers there are a number of possible beneficial consequences of increased lung volume. ${ }^{10} 18$ These include improved buoyancy resulting in a more streamlined body position and therefore less drag in the water, ${ }^{10} 18$ increased surface area for gas exchange, ${ }^{18}$ reduced respiratory oxygen cost at any given submaximal swimming intensity, ${ }^{5}$ and an increased intrapulmonary pressure which would aid expulsion of the blood from the pulmonary vessels. ${ }^{19}$ However, unlike the anthropometrical characteristics of swimmers, which have been shown to be mostly influenced by genetic endowment, ${ }^{20}{ }^{21}$ it is unclear whether the superior lung function found in swimmers is due to genetic influences or is the result of training. ${ }^{3-1018}$ There is a considerable ventilatory strain during swimming, and this appears to increase the conditioning of the accessory muscles of the neck and chest wall. ${ }^{10}$ This may increase maximal static pressure, thus augmenting the swimmer's ability to inflate and deflate the lung. ${ }^{1822}$ Alternatively, swimming training may directly enhance lung growth by some, as yet unknown, mechanism. ${ }^{22}$ This is in contrast with the general population where it has been shown that growth in lung volume is entirely due to growth in body dimensions with no additional effect of changes in the development of physical performance. ${ }^{14-17}$ 23-25 
Most of the studies that have investigated lung volume in swimmers have made comparisons with either matched controls or predicted values. ${ }^{4-7}{ }^{11}$ Few studies have used an allometric modelling approach, ${ }^{89}$ a topic of renewed interest in sport and exercise science. ${ }^{26}$ This technique provides a truly dimensionless expression of data which can be used in subsequent comparisons between groups that differ in body size. ${ }^{27}$ Therefore the aim of this study was to compare lung volume in a large cross sectional sample of swimmers, land based athletes, and sedentary controls by means of allometric scaling.

\section{Methods}

Four hundred and fifty nine asymptomatic white Greek children and adults (10-21 years of age) were tested. Swimmers and land based athletes were admitted on the criterion of training a minimum of three times per week for their respective sports. Land based athletes included subjects who trained and competed in athletics, basketball, canoeing, and rowing Sedentary controls were admitted on the criterion of not being connected with any particular sport and not having a regular exercise programme (that is, with the exception of participating in compulsory physical education classes in school). Before testing, information on subject age, date of birth, and the number of years of training (for land based athletes and swimmers) was obtained verbally from the parent or coach. Static lung function measurements were performed with a portable trans- ducer spirometer (Microlab 3300; Cranlea \& Co, Birmingham, UK). Subjects performed the test in a standing position with a nose clip in place and spirometer held in one hand. After a maximal inhalation, subjects sealed their lips around the mouthpiece and exhaled as hard and as fast as possible. ${ }^{28}$ Subjects were encouraged to continue exhaling for at least one second so that forced expiratory volume for one second $\left(\mathrm{FEV}_{1.0}\right)$ could be measured. Tests were repeated a minimum of three times or until the two highest recorded values - that is, forced vital capacity (FVC) $+\mathrm{FEV}_{1.0}$-varied less than 3\%. Direct measurements included FVC (litres), $\mathrm{FEV}_{1.0}$ (litres), and peak expiratory flow (litres/second). The forced expiratory ratio (\%) was also calculated $\left(\left(\mathrm{FEV}_{1.0} / \mathrm{FVC}\right) \times\right.$ 100). Body mass (kg; Seca 761 scales, $\pm 0.5 \mathrm{~kg}$; Seca Co., Germany) and stature (m; Cranlea JP60 portable stadiometer, $\pm 0.001 \mathrm{~m}$; Cranlea $\& \mathrm{Co})$ were also measured using standardised anthropometric techniques.

The testing took place in various stadia, swimming pools, and state schools in Greece with the full written permission of the subjects and their parents, the Greek National Swimming Federation, and the Physical Education Department of the Dodekanese County.

\section{STATISTICAL ANALYSIS}

Descriptive statistical analysis was performed on all measurements and this was followed by one way analysis of variance to determine differences between groups on these measurements. Where a significant $F$ value was

Table 1 Male and female subject details (mean (SD))

\begin{tabular}{|c|c|c|c|c|c|c|}
\hline & \multicolumn{2}{|l|}{ Swimmers } & \multicolumn{2}{|c|}{ Land based athletes } & \multicolumn{2}{|l|}{ Sedentary } \\
\hline & $\begin{array}{l}\text { Males } \\
(n=82)\end{array}$ & $\begin{array}{c}\text { Females } \\
(n=78)\end{array}$ & $\begin{array}{l}\text { Males } \\
(n=90)\end{array}$ & $\begin{array}{l}\text { Females } \\
(n=72)\end{array}$ & $\begin{array}{l}\text { Males } \\
(n=66)\end{array}$ & $\begin{array}{l}\text { Females } \\
(n=70)\end{array}$ \\
\hline Age (years) & $15.1(3.0)^{\star}$ & $14.5 \quad(2.4)$ & $14.1 \quad(2.6)$ & $14.4 \quad(2.6)$ & $13.8 \quad(2.7)$ & $14.0 \quad(2.5)$ \\
\hline Stature (m) & $1.70(0.13) \dagger$ & $1.63(0.10)^{\star}$ & $1.64(0.15)$ & $1.59(0.10)$ & $1.62(0.14)$ & $1.57(0.10)$ \\
\hline Body mass (kg) & $61.8(14.8)$ & $51.7 \quad(9.8)$ & $59.0(15.6)$ & $50.6 \quad(10.3)$ & $56.3(17.6)$ & $49.2 \quad(10.2)$ \\
\hline
\end{tabular}

* Statistically significant difference (one way analysis of variance, $P<0.05$ ) from sedentary controls.

+ Statistically significant difference (one way analysis of variance, $P<0.05$ ) from land based athletes and sedentary controls.

Table 2 Male lung function values as body temperature, pressure and saturation: observed (mean (SE)) and predicted (by gender, stature, age, \%) values ${ }^{29}$

\begin{tabular}{|c|c|c|c|c|c|c|}
\hline & \multicolumn{2}{|c|}{ Swimmers $(n=82)$} & \multicolumn{2}{|c|}{ Land based athletes $(n=90)$} & \multicolumn{2}{|c|}{ Sedentary $(n=66)$} \\
\hline & Observed & Predicted & Observed & Predicted & Observed & Predicted \\
\hline FVC (litres) & $4.5(1.3)^{\star}$ & $103^{\star}$ & $3.9(1.3)$ & 96 & $3.5(1.1)$ & 90 \\
\hline $\mathrm{FEV}_{1.0}$ (litres) & $4.1(1.2)^{\star}$ & $111^{\star}$ & $3.4(1.1)$ & 102 & $3.1(0.9)$ & 97 \\
\hline FER $(\%)$ & $90.9(5.9)$ & - & $89.2(5.2)$ & - & $89.9(5.9)$ & - \\
\hline PEF (litres/second) & $488(135)^{\star}$ & $96^{\star}$ & $410 \quad(128)$ & 88 & $381 \quad(111)$ & 83 \\
\hline
\end{tabular}

FVC, forced vital capacity; $\mathrm{FEV}_{1,0}$, forced expiratory volume in one second; FER, forced expiratory ratio; PEF, peak expiratory flow. * Statistically significant difference (one way analysis of variance, $P<0.05$ ) from land based athletes and sedentary controls.

Table 3 Female lung function values as body temperature, pressure and saturation: observed (mean (SE)) and predicted (by gender, stature, age, \%) values ${ }^{29}$

\begin{tabular}{|c|c|c|c|c|c|c|}
\hline & \multicolumn{2}{|c|}{ Swimmers $(n=78)$} & \multicolumn{2}{|c|}{ Land based athletes $(n=72)$} & \multicolumn{2}{|c|}{ Sedentary $(n=70)$} \\
\hline & Observed & Predicted & Observed & Predicted & Observed & Predicted \\
\hline FVC (litres) & $3.5(0.8)^{\star}$ & $104^{\star}$ & $3.3(0.7) \dagger$ & $96 \dagger$ & $2.9(0.6)$ & 91 \\
\hline $\mathrm{FEV}_{10}$ (litres) & $3.3(0.7)^{\star}$ & $111^{\star}$ & $2.9(0.6)$ & 99 & $2.7(0.6)$ & 102 \\
\hline FER $(\%)$ & $93.4(5.8)$ & - & $91.9(5.0)$ & - & $93.7(4.7)$ & - \\
\hline PEF (litres/second) & $396(78)^{\star}$ & $95^{\star}$ & 364 (74) $\dagger$ & $91+$ & $329 \quad(85)$ & 83 \\
\hline
\end{tabular}

FVC, forced vital capacity; $\mathrm{FEV}_{10}$, forced expiratory volume in one second; FER, forced expiratory ratio; PEF, peak expiratory flow.

* Statistically significant difference (one way analysis of variance, $P<0.05$ ) from land based athletes and sedentary controls.

+ Statistically significant difference (one way analysis of variance, $P<0.05$ ) from sedentary controls. 


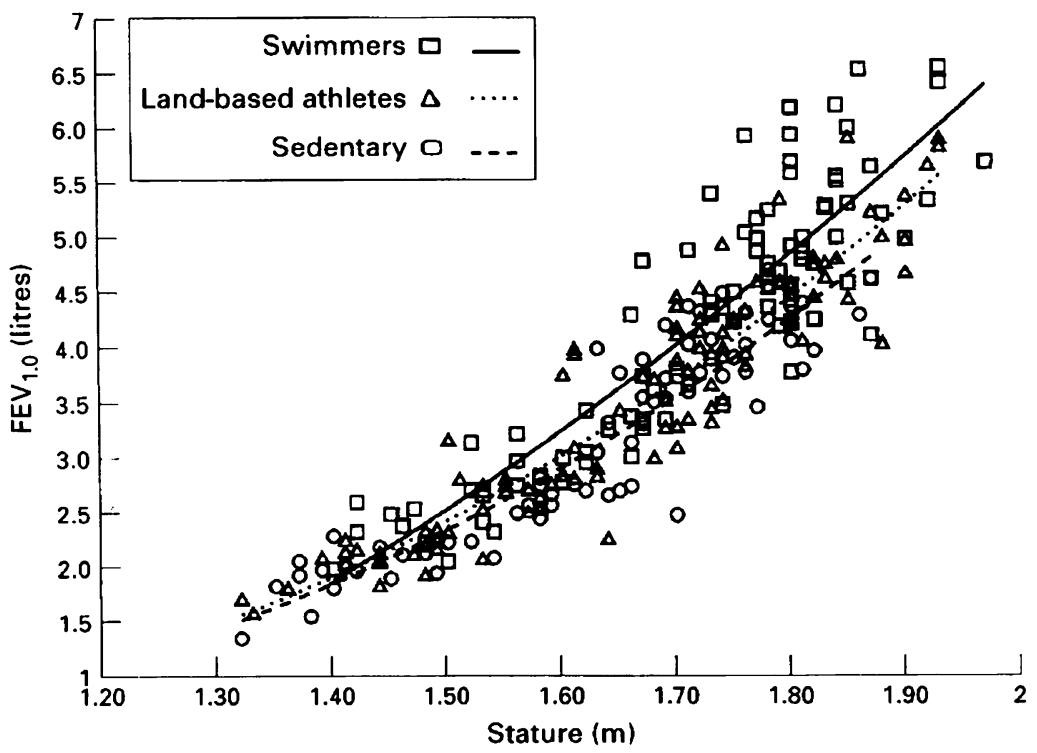

Figure 1 Male power functional relationships between $F E V_{1.0}$ and stature.

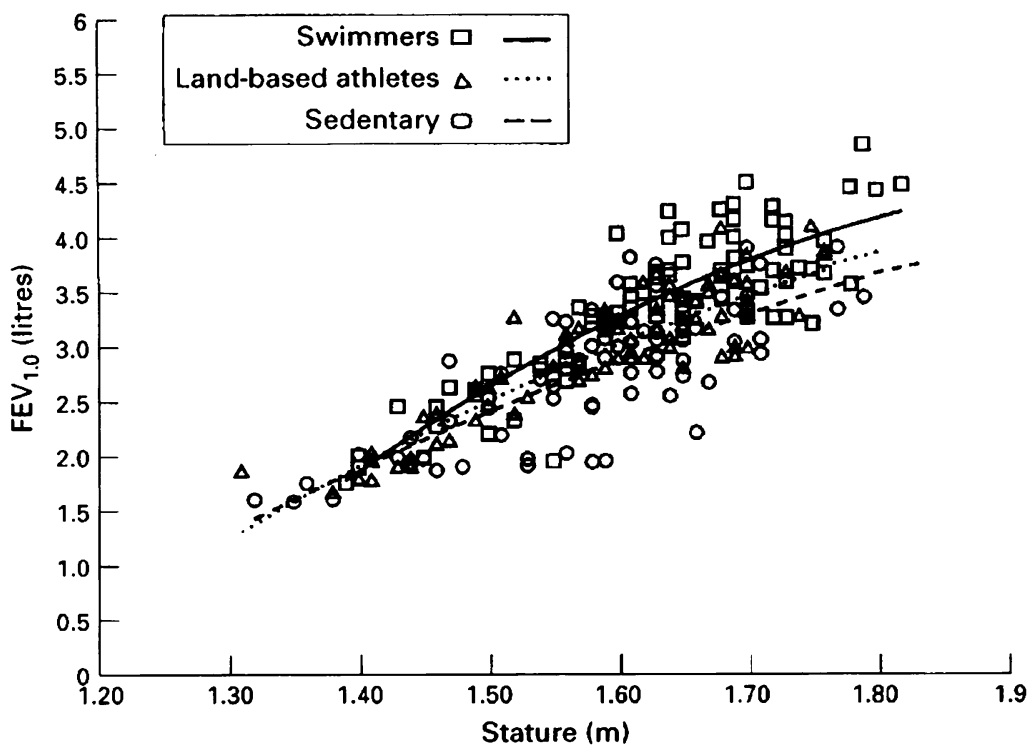

Figure 2 Female power functional relationships between FEV ${ }_{1.0}$ and stature.

Table $4 \quad F E V_{1.0} /$ stature $^{b *}$ analysis of variance for males

\begin{tabular}{lllllll}
\hline Source & $\begin{array}{l}\text { Degrees of } \\
\text { freedom }\end{array}$ & $\begin{array}{l}\text { Sum of } \\
\text { squares }\end{array}$ & Mean & F squares & F ratio & Probability (P) \\
\hline Between groups & 235 & 2 & 0.65 & 0.32 & 23.6 & $<0.001$ \\
Within groups & 23.23 & 0.01 & & & \\
Total & 237 & 3.88 & & & & \\
\hline
\end{tabular}

${ }^{\star} 0.64(0.18)$ litres $/ \mathrm{m}^{2.69}(\operatorname{mean}(\mathrm{SE}))$.

Table $5 F E V_{1.0} /$ stature $^{b *}$ analysis of variance for females

\begin{tabular}{lllllll}
\hline Source & $\begin{array}{l}\text { Degrees of } \\
\text { freedom }\end{array}$ & $\begin{array}{l}\text { Sum of } \\
\text { squares }\end{array}$ & Mean & F squares & F ratio & Probability (P) \\
\hline Between groups & 219 & 2 & 0.60 & 0.30 & 20.7 & $<0.001$ \\
Within groups & 219 & 3.20 & 0.02 & & & \\
Total & 221 & 3.80 & & & & \\
\hline
\end{tabular}

$\star 0.33(0.24)$ litres $/ \mathrm{m}^{2.32}(\mathrm{mean}(\mathrm{SE}))$.

obtained $(P<0.05)$, the post hoc Scheffe's procedure was used to identify significantly different groups. In order to control for the effects of stature and age, an allometric modelling approach was used based on the recommendations of Nevill and Holder. ${ }^{26}$ This was preceded by Pearson Product Moment correlation coefficients to determine the degree of relationship
Table 6 Male and female FEV ${ }_{1.0}$ stature $^{b \star}$ values (mean (SE))

\begin{tabular}{llll}
\hline & Swimmers & $\begin{array}{l}\text { Land based } \\
\text { athletes }\end{array}$ & Sedentary \\
\hline Males & $0.63(0.008)^{\mathrm{a}}$ & $0.58(0.008)$ & $0.57(0.007)$ \\
Females & $0.71(0.008)^{\mathrm{a}}$ & $0.67(0.012)^{\mathrm{c}}$ & $0.64(0.091)$ \\
\hline
\end{tabular}

$\star 0.64(0.18)$ litres $/ \mathrm{m}^{2.69}$ and $0.33(0.24)$ litres $/ \mathrm{m}^{2.32}$ for males and females respectively (mean(SE)).

a Statistically significant difference $(P<0.05)$ from land based athletes and sedentary controls.

c Statistically significant difference $(P<0.05)$ from sedentary controls.

between the lung function parameters and subject characteristics. Logarithmic transformations were performed on $\mathrm{FEV}_{1.0}$ and stature in men and women, and these logarithmically transformed data were used to determine the exponent in the following allometric equation, ${ }^{26}$ :

$\mathrm{FEV}_{1.0}=$ stature $^{\mathrm{k}} \times \exp (\mathrm{c}+(\mathrm{d} \times$ age $)+(\mathrm{e} \times$ age $\left.)^{2}\right) \epsilon$

where $k, c, d$, and e are constants, and $\epsilon=$ error term.

Again, to determine if there were statistical differences between swimmers, land based athletes, and sedentary controls, a one way analysis of variance was performed on the resulting power function ratios. ${ }^{26}$ An independent $t$ test on the power function ratios of the male and female national standard swimmers and nonnational standard swimmers was also performed. In addition, an independent $t$ test was performed on the number of years of training for national standard swimmers $v$ non-national standard swimmers. Finally, analysis of covariance was performed on the power function ratios of the national standard swimmers $v$ non-national standard swimmers, with years of training used as the covariate. The level of statistical significance was set at $\mathrm{P}<0.05$.

\section{Results}

Tables 1-3 present the subject characteristics. The results for the different groups are similar to values obtained previously in either

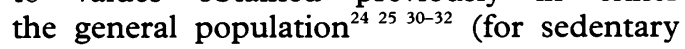
controls and land based athletes) or swimmers. ${ }^{1-11} 1822$ 33-35 As expected, both male and female swimmers had superior peak expiratory flow, FVC, and $\mathrm{FEV}_{1.0}$ compared with land based athletes and sedentary controls (figs 1 and 2), but the swimmers were also taller than land based athletes and sedentary controls. In addition, male swimmers were older than male land based athletes and sedentary controls (table 1).

Pearson Product Moment correlation coefficients showed that $\ln \mathrm{FEV}_{1.0}$ was related to $\ln$ stature in males and females $(r=0.93$ and 0.86 respectively, $\mathrm{P}<0.001)$. When combined with age and age ${ }^{2}$, the explained variance $\left(R^{2}\right)$ in $\mathrm{FEV}_{1.0}$ was $76 \%$ and $88 \%$ for females and males respectively. Resulting power functions, $\mathrm{FEV}_{1.0}$ /stature ${ }^{\mathrm{b}}$, were $0.64(0.18) \mathrm{litres} / \mathrm{m}^{2.69}$ and $0.33(0.24)$ litres $/ \mathrm{m}^{2.32}$ for males and females respectively (mean (SE)). These exponents are very similar to values previously reported in the literature. ${ }^{30-32}$ The subsequent one way analysis of variance on the power functions showed significant $F$ values $(\mathrm{P}<0.001)$ for both males 
Table 7 Male and female $F E V_{1.0}$ values for national and non-national standard swimmers (mean $(S E)$ )

\begin{tabular}{llllll}
\hline & National & & & \multicolumn{2}{l}{ Non-national } \\
\cline { 2 - 3 } \cline { 5 - 6 } \cline { 5 - 6 } & Males $(n=37)$ & Females $(n=24)$ & & Males $(n=39)$ & Females $(n=13)$ \\
\hline $\mathrm{FEV}_{1.0}$ (litres) & $5.02(0.14)^{\mathrm{a}}$ & $3.68(0.09)$ & & $4.20(0.19)$ & $3.59(0.08)$ \\
$\mathrm{FEV}_{1.0} /$ stature $^{\mathrm{b}}$ & $1.03(0.022)^{\mathrm{a}}$ & $1.11(0.015)$ & & $0.93(0.023)$ & $1.08(0.029)$ \\
\hline
\end{tabular}

$\star 0.64(0.18)$ litres $/ \mathrm{m}^{2.69}$ and $0.33(0.24)$ litres $/ \mathrm{m}^{2.32}$ for males and females respectively (mean(SE))

${ }^{2}$ Statistically significant difference $(t$ test, $\mathrm{P}<0.05)$ from data for non-national standard males.

Table 8 Details of male and female national and non-national standard swimmers $(\operatorname{mean}(S D))$

\begin{tabular}{|c|c|c|c|c|}
\hline & \multicolumn{2}{|l|}{ National } & \multicolumn{2}{|l|}{ Non-national } \\
\hline & Males $(n=37)$ & Females $(n=24)$ & Males $(n=39)$ & Females $(n=13)$ \\
\hline Age (years) & $18.9(3.7)^{\star}$ & 16.1 & 16.5 & $16.5(1.9)$ \\
\hline Stature $(\mathrm{m})$ & $1.79(0.07)^{\star}$ & $1.67(0.07)$ & $1.73(0.10)$ & $1.68(0.06)$ \\
\hline Body mass (kg) & $71.8(10.4)^{\star}$ & $55.4(8.1)$ & $63.7(13.1)$ & $56.5(5.0)$ \\
\hline Years of training & $10.5(3.8) \dagger$ & $7.0 \quad(2.7) \dagger$ & $8.1 \quad(3.1)$ & $4.6 \quad(1.3)$ \\
\hline
\end{tabular}

* Statistically significant difference from male non-national standard swimmers $(t$ test, $\mathrm{P}<0.05)$

+ Statistically significant difference from non-national standard swimmers $(t$ test, $\mathrm{P}<0.01)$.

Table $9 \mathrm{FEV} V_{1.0} /$ stature $^{h}$ analysis of covariance (years of training = covariate) for male swimmers

\begin{tabular}{lcllll}
\hline Source & $\begin{array}{l}\text { Degrees of } \\
\text { freedom }\end{array}$ & $\begin{array}{l}\text { Sum of } \\
\text { squares }\end{array}$ & Square & $\begin{array}{l}\text { Mean } \\
\text { ratio }\end{array}$ & F probability \\
\hline Years of training & 1 & 0.096 & 0.096 & 7.3 & $>0.01$ \\
National/non-national & 1 & 0.017 & 0.017 & 1.3 & 0.26 \\
Explained & 2 & 0.174 & 0.087 & 6.6 & $>0.01$ \\
Residual & 110 & 1.5 & 0.013 & & \\
Total & 112 & 1.68 & 0.014 & &
\end{tabular}

$\star 0.64(0.18)$ litres $/ \mathrm{m}^{2.69}($ mean $(\mathrm{SE}))$.

Table $10 \mathrm{FEV} V_{1.0} /$ stature $^{\natural *}$ analysis of covariance (years of training = covariate) for female swimmers

\begin{tabular}{lcllll}
\hline Source & $\begin{array}{l}\text { Degrees of } \\
\text { freedom }\end{array}$ & $\begin{array}{l}\text { Sum of } \\
\text { squares }\end{array}$ & Square & $\begin{array}{l}\text { Mean } \\
\text { ratio }\end{array}$ & F probability \\
\hline Years of training & 1 & 0.343 & 0.343 & 15.4 & $>0.01$ \\
National/non-national & 1 & 0.019 & 0.019 & 0.88 & 0.35 \\
Explained & 2 & 0.362 & 0.181 & 8.2 & $>0.01$ \\
Residual & 110 & 2.5 & 0.022 & & \\
Total & 112 & 2.8 & 0.014 & & \\
\hline
\end{tabular}

$\star 0.33(0.24)$ litres $/ \mathrm{m}^{2.32}(\operatorname{mean}(\mathrm{SE}))$.

and females (tables 4 and 5). The post hoc Scheffe's procedure showed that the swimming group had larger $\mathrm{FEV}_{1.0}$ than both land based athletes and sedentary controls (table 6).

The independent $t$ test on the power function ratios showed that male national standard swimmers had superior $\mathrm{FEV}_{1.0}$ compared with male non-national standard swimmers $(P<0.05$; table 7$)$. However, the national standard swimmers commenced training at a younger age and had therefore trained for a longer period of time than the non-national standard swimmers (10.5 (3.8) years $v 8.1$ (3.1) years; $\mathrm{P}<0.05$; table 8 ). When years of swimming training was controlled for by analysis of covariance, the differences in $\mathrm{FEV}_{1.0}$ between the two groups was no longer evident (tables 9 and 10).

\section{Discussion}

The results of this study support previous work indicating that lung volume is increased in young male and female swimmers compared with both sedentary subjects ${ }^{13-7}$ and land based athletes. ${ }^{4-11}$ Indeed, our results show that female swimmers have absolute lung volumes similar to male land based athletes and seden- tary control groups (tables 2 and 3 ). While land based athletes and sedentary control groups have "normal" values in relation to age, stature, and sex, both male and female swimmers have $\mathrm{FEV}_{1.0}$ values about $11 \%$ higher than predicted values. These results are in agreement with previous studies that have measured lung volume in swimmers. ${ }^{13-8}$ 9-11 1822 33-35 To what extent the superior lung volume in swimmers is a consequence of training, and to what extent it may be due to natural endowment is equivocal. In swimming, the load of the water pressure against the chest wall and elevated airway resistance as the result of immersion could comprise a conditioning stimulus as well as the requirement that inspirations must occur rapidly from functional residual capacity during short intervals between strokes. ${ }^{18}$ On the other hand, there is also support in the literature for a substantial contribution from genetic endowment to the enhanced lung function in swimmers. Baxter-Jones and Helms $^{9}$ studied a sample of 231 highly trained male swimmers, gymnasts, and soccer and tennis players. Of the four sports, the swimmers had the highest initial lung volume in each of five age cohorts $(8,10,12,14,16$ years). Having controlled for factors such as age, stature, body mass, and training hours, multilevel regression analysis showed that the difference in lung size between the sports did not change with time. Ericksson $e t a l^{3}$ have also noted that increased lung volume was already present in a group of 10 year old boys $(n=18)$ who had just begun swimming training. Furthermore, other studies were unable to detect lung volume increases in child swimmers after six or seven months of training. ${ }^{34}{ }^{35}$ Because of the cross sectional nature of the present study, the results cannot exclude genetic endowment as a major determinant of the superior lung volume observed in elite swimmers. Zinman and Gaultier $^{22}$ have suggested that to differentiate natural endowment from adaptive growth, it is necessary to examine the mechanical characteristics of the respiratory system of swimmers in more detail. Their work brings attention to the disproportionate development of air spaces in normal children, and this development has been noted to be even more pronounced as a result of adaptive growth in high altitude dwellers. ${ }^{36}$ Cotes $^{37}$ points out that the increased lung volume observed in residents of high altitude may be the direct consequence of a combination of hypoxaemia and a high level of habitual physical activity during childhood rather than the stress of hypoxaemia alone. Documentation of a greater disproportionate development of air spaces in swimmers compared with controls would support the hypothesis that swimmers have larger lung volume as the result of adaptive growth rather than genetic endowment. ${ }^{22}$

The results further suggest that the most successful male swimmers-that is, the national standard swimmers - have larger lung volumes than non-national standard swimmers. This appears to be the first instance that such a difference between elite and subelite swimmers has been highlighted. A possible 
reason for the difference between the two groups is an increased strength of the respiratory musculature, a factor that contributes to forced manoeuvres, since there is evidence of a positive relationship between upper-body strength and swim performance. ${ }^{38}$ Further analysis of the data showed that, when years of training was controlled for by analysis of covariance, the differences in $\mathrm{FEV}_{1.0}$ between the two groups was no longer evident. This suggests that the number of years of swimming training and/or the earlier age at which swimming training begins may have a significant bearing on subsequent $\mathrm{FEV}_{1.0}$ and swimming performance. Interestingly, these differences were not evident between the female national and non-national standard swimmers. It is known that in the general population, muscle strength in itself explains the apparent "acceleration" in male lung volume with increased stature after puberty, ${ }^{20}$ and it may be that this also holds true for male and female swimmers. The inclusion of a measurement of respiratory muscle strength might therefore be a useful addition to future studies of lung volume of elite $v$ non-elite male and female swimming groups.

In summary, our results support previous work that suggests that swimmers have superior $\mathrm{FEV}_{1.0}$ independent of age and stature in comparison with both land based athletes and sedentary controls. In addition, male national standard swimmers were shown to have superior $\mathrm{FEV}_{1.0}$ independent of age and stature in comparison with male non-national standard swimmers. When years of training was controlled for, the difference in $\mathrm{FEV}_{1.0}$ between these two groups was no longer evident. This suggests that the years of swimming training and/or the earlier age at which training begins may have a significant influence on subsequent $\mathrm{FEV}_{1.0}$ and swimming performance. However, until additional longitudinal studies are completed examining selection, respiratory muscle strength, and training patterns (including training duration and intensity) in more detail, the relative contribution of genetic endowment and training to enhanced lung volume in swimmers will remain unclear.

The authors express their appreciation to Michael Hughes and Pirkko Korkia (University of Luton) for their critical review of the manuscript.

1 Astrand PO, Engstrom L, Eriksson BO, Karlberg P, Astrand PO, Engstrom L, Eriksson BO, Karlberg P,
Nylander I, Saltin B, et al. Girl swimmers with special reference to respiratory and circulatory adaptations and erence to respiratory and circulatory adaptations and gynaecological and

2 Malina RM. Physical growth and maturity characteristics of young athletes. In: Magill R, Ash T, Small F, eds. Children in sport. Champaign, Illinois: Human Kinetics, 1982:15-25.

3 Andrew GN, Becklake MR, Guleria JS, Bates DV. Heart and lung functions in swimmers and nonathletes during growth. F Appl Physiol 1972;32:245-51.

4 Bloomfield J, Blansby BA, Ackland TR, Elliot BC. The anatomical and physiological characteristics of pre-pubertal adolescent swimmers, tennis players and non competitors. Austr F Sci Med Sport 1985;17:19-23.

5 Godfrey R, Bailey D, Roberts J, Davies B, Fullerton F. Comparison of lung function values in "elite" male, age group swimmers with "normally" active schoolboys of the same age. In Ring FJ, ed. First Bath Sports Medicine Conference, 7-8 July, 1995, Bath: University of Bath, 1995; 149-151.

6 Magel JR, Andersen KL. Pulmonary diffusing capacity and cardiac output in young trained Norwegian swimmers and untrained subjects. Med Sci Sports 1969;1:131-9.
7 Newman F, Smalley BF, Thomson ML. A comparison between body size and lung function of swimmers and normal school children. 7 Physiol (Lond) 1961;156:9-10P.

8 Nevill A, Baxter-Jones ADG, Helms P. Modelling the developmental changes in lung function on female athletes during puberty and adolescence. In Brewer J, ed. British ing puberty and adolescence. In Brewer J, ed. British Association of Sport and Exercise Sciences Annual Conference,
Lilleshall, UK, 7-9 Sept 1996, Leeds: British Association of Sports and Exercise, 1996:122.

9 Baxter-Jones ADG, Helms PJ. Growth of lung function in male athletes during puberty and adolescence. Eur Respir $\mathcal{F}$ 1993;6:222-5.

10 Cordain L, Stager J. Pulmonary structure and function in swimmers. Sports Med 1988;6:271-8.

11 Cordain L, Tucker A, Moon D, Stager J. Lung volumes and maximal respiratory pressures in collegiate swimmers and runners. Res $Q$ Exerc Sport 1990;61:70-4.

12 Reilly T, Secher N, Snell P, Williams C. In: Physiology of sports. London: E \& F N Spon, 1990:238-9.

13 Dempsey JA, Gledhill N, Reddan WG, Forster HV, Hanson PG, Claremont AD. Pulmonary adaptations to exercise: effects of exercise type and duration, chronic hypoxia and physical training. Ann N Y Acad Sci 1977;301:243-61.

14 Adams WC. Effect of a season of varsity track and field on selected anthropometric, circulatory and pulmonary function parameters. Res $Q$ 1968;39:5-16.

15 Kollias J, Boileau RA, Bartlett HL, Buskirk ER. Pulmonary function and physical conditioning in lean and obese subjects. Arch Environ Health 1972;25:146-50.

16 Reuschlein PS, Reddan WG, Burpee J, Gee JBL, Rankin J. Effect of physical training on the pulmonary diffusing capacity during submaximal work. $F$ Appl Physiol 1968;24: 152-8.

17 Sinning WE, Adrian MJ. Cardio-respiratory changes in college women due to a season of competitive basketball. $f$ Appl Physiol 1968;25:720-4.

18 Clanton T, Dixon GF, Drake J, Gadek JE. Effects of swim training on lung volumes and inspiratory muscle conditioning. 7 Appl Physiol 1987;62:39-46.

19 Shephard RJ. Exercise and the lungs. In: Alexander JF, Serfass RC, Tipton CM, eds. Fitness and exercise. Chicago: Athletic Institute, 1972:7-18.

20 Bar-Or O, Unithan V, Illescas C. Physiologic considerations in age group swimming. Med Sport Sci 1994;39:199-205.

21 Peltenburg AL. Growth and biological development of female athletes. Utrecht: Elinkwijk, 1984.

22 Zinman R, Gaultier C. Maximal static pressures and lung volumes in young female swimmers. Respir Physiol 1986;64: 229-39.

23 Andersen KL, Rutenfranz J, Seliger V, Ilmarinen J, Berndt I, Kylian $\mathrm{H}$, et al. The growth of lung volumes affected by physical performance capacity in boys and girls during childhood and adolescence. Eur $\mathcal{F}$ Appl Physiol 1984;52: 380-4.

24 Rosenthal M, Bain, SH, Cramer D, Helms P, Denison D, Bush A, Warner JO. Lung function in white children aged 4 to 19 years: I. Thorax 1993;48:794-802.

25 Biersteker MWA, Biersteker PA. Vital capacity in trained and untrained healthy young adults in the Netherlands. Eur f A ppl Physiol 1985;54:46-53.

26 Nevill AM, Holder RL. Scaling, normalizing and per ratio standards: an allometric modelling approach. $\mathcal{f}$ Appl Physiol 1995;79:1027-31

27 Schmidt-Nielsen K. Scaling; why is animal size so important? Cambridge: Cambridge University Press, 1984.

28 Cotes JE. Lung function: assessment and application in medicine, 4th ed. Oxford: Blackwell Scientific, 1979:101-4.

29 European Community for Coal and Steel. Standardisation of lung function. Bulletin European de Physiopathologie Respiratoire 1983;19:22-7.

30 Lyons HA, Tanner RW. Total lung volumes and its subdivisions in children: normal standards. $\mathcal{F}$ Appl Physiol 1962;17: 601-4.

31 DeMuth GR, Howatt WF, Hill BM. Lung volumes. Pediatrics 1965;35(suppl 162-175)

32 Polgar G, Promadhat V. Pulmonary function testing in children: techniques and standards. Philadelphia: WB Saunders Co, 1971 .

33 Eriksson BO, Engstrom I, Karlberg P, Lundin A, Saltin B, Thoren C. Long term effect of previous swimming training in girls: a 10 year follow-up of the "Girl Swimmers". Acta Paediatr Scand 1978;67:285-92.

34 Gibbons JA, Cunningham DA, Shaw DB, Fynon RB. The effect of swimming training on selected aspects of pulmonary function of young girls: a preliminary report. In: Taylor AW, ed. Training: scientific basis and application. Springfield, NJ: Thomas, 1972

35 Vaccaro P, Clarke DH. Cardiorespiratory alterations in 9 to 11 year old children following a season of competitive swimming. Med Sci Sports 1978;10:204-7.

36 Hashimoto A, Carlson NA, Derion T, Lanphier EH Reddan WG. Effects of posture and immersion on diaphragmatic function during forced respiratory manoeuvres. Federation Proceedings 1984;43:531.

37 Cotes JE. Lung function: assessment and application in medicine, 4th ed. Oxford: Blackwell Scientific, 1979:352-3.

38 Sharp R, Troup JP, Costill DL. Relationship between power output and sprint freestyle swimming. Med Sci Sports Exerc 1982;14:53-6 